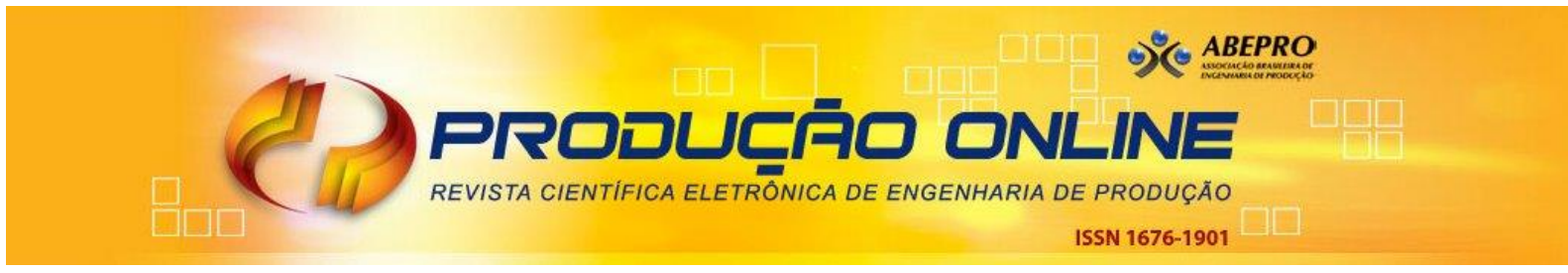

\title{
O COMPORTAMENTO DE CONSUMIDORES DE VEÍCULOS USADOS: UM ESTUDO A PARTIR DO PROCESSO DECISÓRIO DE COMPRA
}

\section{THE USED VEHICLES CONSUMER BEHAVIOR: A STUDY BASED ONTHE PURCHASE DECISION-MAKING PROCESS}

\author{
Tiago Eckert Klockner*Email: tiago.klockner@unijui.edu.br \\ Luciano Zamberlan*Email: lucianoz@unijui.edu.br \\ Ariosto Sparemberger* Email: ariosto@unijui.edu.br \\ Pedro Buttenbender* Email: pedrolb@unijui.edu.br \\ Gabriela Cappellari* Email: gabriela.cplr@gmail.com \\ Jorge Oneide Sausen* Email: josausen@unijui.edu.br \\ * Universidade Regional do Noroeste do Estado do Rio Grande do Sul (UNIJUÍ), ljuí, RS
}

\begin{abstract}
Resumo: O consumidor tornou-se mais exigente e ciente de seus direitos, além de contar com uma grande quantidade de ofertas e opções que lhe permite escolher o produto que de fato seja a melhor opção para satisfazer suas necessidades e desejos. Com essa mudança de comportamento, o consumidor passou a avaliar melhor suas opções de compra antes de realizá-las. Diante disso, o presente estudo aborda o processo decisório de compra de veículos usados e tem como propósito avaliar as atitudes do consumidor diante de cada etapa desse processo. A pesquisa classifica-se como sendo de caráter exploratório e descritivo. Na etapa exploratória, de abordagem qualitativa, efetuou-se um grupo de foco com consumidores de veículos e ainda entrevistas em profundidade com proprietários de revendas de automóveis, ambos com o intuito de identificar as variáveis a serem usadas para a elaboração do questionário. Na parte descritiva realizou-se um survey, onde foi aplicado um questionário a 86 compradores de veículos usados por meio de entrevistas pessoais. A análise dos dados se deu por meio da distribuição de frequência e Teste $T$. Os resultados aduzem que $o$ atendimento e a sinceridade percebida nos vendedores são algumas das características que os consumidores mais consideram importantes para realizar uma compra. Os benefícios e características que os veículos possuem também foram fatores muito considerados, bem como a procedência e o estado de conservação dos mesmos. Por fim, os resultados contribuem na elaboração de estratégias de marketing para o setor e ainda para qualificar o relacionamento entre as empresas e seus clientes.
\end{abstract}

Palavras-chaves: Comportamento do consumidor. Processo decisório de compra. Veículos usados.

Abstract: Consumers have become more demanding and aware of their rights. Furthermore, there are many offers and options that allow them to choose the product that really fit their needs and desires. With this change in behavior, consumers are better assessing their buying options before performing them. Facing that, the present study addresses the decision-making process of buying used vehicles and aims to evaluate consumer's behavior at each stage of this process. The research is classified as exploratory and descriptive. In the exploratory stage, using a qualitative approach, was performed a focus group with vehicle consumers and interviews with car dealers, both in order to identify the variables to be used for the preparation of the questionnaire. In the descriptive part, it was carried out a survey, which was applied by questionnaire to 86 purchasers of used vehicles through personal interviews. Data analysis was done through frequency distribution and T. Test Results adduce that the service and perceived sincerity of the sellers are the features that consumers consider most important to make a purchase. The benefits and vehicles features have been also a very factor considered, as well as the origin and the state of conservation of the same. Finally, the results contribute to the development of marketing strategies for the sector and also to describe the relationship between companies and their clients.

Revista Produção Online, Florianópolis, SC, v. 16, n. 2, p. 705-721, abr./jun. 2016. 
Keywords: Consumer behavior. Decision-making process of buying. Used vehicles.

\section{INTRODUÇÃO}

O mercado de automóveis no Brasil teve uma expansão em grande escala na última década. Com o aumento significativo das vendas e a consequente transformação no cenário, como crescimento da indústria e da empregabilidade, o país passou por uma evolução econômica. As empresas participantes deste setor passaram a faturar muito com a nova era do mercado de automóveis, sendo elas responsáveis por grande parte do desenvolvimento da economia brasileira nos últimos anos.

Com o aumento do poder aquisitivo da população, juntamente com as facilidades de financiamentos e a grande quantidade de opções em modelos oferecidas pelas lojas e concessionárias de veículos, o sonho de aquisição de um veículo se torna cada vez mais realidade no cenário atual. Por outro lado, o processo de decisão e fidelização desses potenciais consumidores passou a ficar mais complexo (MECCA; COLAUTO; BEUREN, 2005); uma vez que, expostos a uma enorme quantidade de informações e, na maioria das vezes, obedecendo a uma necessidade de adaptar ao seu estilo de vida, a escolha de um veículo passou a envolver diferentes fatores, tais como: família, segurança, conforto, qualidade, status, entre outros.

O consumidor atual tornou-se mais exigente e ciente de seus direitos, além de contar com uma grande quantidade de ofertas e opções que lhe permite escolher o produto que de fato seja a melhor opção para satisfazer suas necessidades e desejos. Com essa mudança de comportamento, o consumidor passou a avaliar melhor suas opções de compra antes de realizá-las, atraindo a atenção de muitos pensadores do tema (CHEN, 2006).

Diante do exposto, Saaty (2008) ressalta que todas as ações são consciente ou inconscientemente resultado de alguma decisão. Assim, ressalta-se que os estudos sobre o comportamento do consumidor são fundamentais para compreender como e o que ele deseja adquirir (BARROS; LOPES; WANDERLEY, 2007). Schiffman e Kanuk (2000) asseveram ainda que o estudo do comportamento do consumidor busca avaliar como os indivíduos tomam decisões em gastar seus 
recursos disponíveis, tais como tempo, dinheiro, esforço e, ainda, o que compram, quando compram, onde, com qual frequência compram e usam o que compram.

Destarte, o presente estudo objetiva avaliar as atitudes dos consumidores de veículos usados, procurando compreender suas percepções acerca desse processo, com o intuito de contribuir com as organizações que atuam nesse segmento. Assim, esta pesquisa encontra-se estruturada da seguinte forma: inicialmente se apresentam as referências teóricas a respeito do processo decisório de compra; após, são descritos os procedimentos metodológicos que foram utilizados para a realização do estudo; e, posteriormente, são apresentados os resultados da pesquisa, conclusões e as referências bibliográficas.

\section{PROCESSO DECISÓRIO DE COMPRA}

Na concepção de Sheth, Mittal e Newman (2001), as decisões dos clientes incluem fatores, como: se deve ser feita a compra, o que comprar, quando comprar e também de quem comprar. Os autores destacam ainda que os clientes têm certa quantia de tempo e dinheiro para comprar e, com isso, devem usufruir os mesmos de maneira coerente. Schiffman e Kanuk (2000) afirmam que, na maioria das vezes, existe uma escolha; assim, existe quase sempre uma oportunidade para os consumidores avaliarem e tomarem sua decisão.

Kotler (2000, p.199) assevera que "a tomada de decisão do consumidor no ato da compra varia de acordo com o tipo de decisão de compra". Na ótica de Mintzberg, Raisinghani e Théorêt (1976), o processo decisório consiste num conjunto de ações e fatores que se comportam de forma dinâmica. Esse processo inicia-se quando ocorre a identificação de um estímulo para a ação e é encerrado quando há o engajamento específico para agir.

Nutt (1993) destaca que os processos e os procedimentos que constituem a decisão assumem papel determinante e podem levar a desfechos diferenciados. Neste sentido, para este estudo o modelo de processo decisório de compra adotado é o descrito por Engel, Blackwell e Miniard (2000), que leva em consideração sete estágios: reconhecimento da necessidade, busca de informação, avaliação das alternativas, compra, consumo, avaliação pós-consumo e descarte. A seguir, cada uma destas etapas será abordada separadamente. 
O reconhecimento de uma necessidade acontece quando um indivíduo sente a diferença entre o que ele percebe ser a situação ideal, comparada com a situação real em algum momento; ou seja, é um desejo que inicia o processo decisório (ENGEL; BLACKWELL; MINIARD, 2000). Para Kotler (2000), o processo de compra começa quando o comprador reconhece um problema ou uma necessidade, a qual pode ser provocada por estímulos internos como também externos.

$\mathrm{Na}$ perspectiva de Engel, Blackwell e Miniard (2000), a segunda fase do processo de decisão, que vem a ser a da busca, é definida como a ativação do conhecimento armazenado na memória. A busca pode ser interna ou externa, sendo que na primeira os consumidores buscam na memória informações relevantes que permitam uma ação satisfatória como, por exemplo, uma compra bem-sucedida anteriormente; assim, pode ser suficiente então a busca interna. Na busca externa o consumidor reúne informações adicionais no ambiente.

Engel, Blackwell e Miniard (2000) definem avaliação de alternativa como o processo pelo qual uma alternativa de escolha é avaliada e considerada suficiente para atender as necessidades do consumidor. Quando o processo de avaliação de consumo for de natureza habitual, o consumidor precisa somente formar a intenção de comprar ou recomprar o mesmo produto. Quando a avaliação for em produtos duráveis e de alto valor, o processo torna-se complexo.

Sheth, Mittal e Newman (2001) subdividem o ato da compra em três fases para melhor explicá-lo. A primeira fase seria a identificação da alternativa preferida, quando o cliente sabe qual é o produto que ele quer. Na segunda fase, o cliente precisa criar uma intenção de compra, ou seja, estar determinado a realizar a compra na primeira oportunidade que surgir. $\mathrm{O}$ terceiro e último passo seria efetuar a compra, obter através do vendedor a transferência de direito, pagar o produto e se apossar do mesmo.

Schiffman e Kanuk (2000) comentam que é importante o consumidor fazer uma "visão do consumo" antes de tomar qualquer decisão. Essa visão seria, por exemplo, uma pessoa avaliar duas opções de férias, uma esquiando ou estando no caribe. Essa prática possibilita ao consumidor participar mentalmente de várias alternativas, até que chegue a uma decisão que contemple as expectativas esperadas. Giglio (1996) apregoa que, depois de decidida a compra, o processo de consumo não termina, as pessoas realizarão uma comparação entre o que 
imaginavam obter com a compra (as expectativas) e o que percebem estar obtendo (como veem sua vida no momento).

Na visão de Engel, Blackwell e Miniard (2000), após a compra e o consumo de um produto ou serviço virão os resultados de duas formas: satisfação ou insatisfação. Todos os que realizam uma compra têm certas expectativas. A satisfação, que é o resultado esperado, é vista como uma avaliação pós-compra de uma alternativa escolhida, que pelo menos atende ou excede as expectativas, caso contrario haverá a insatisfação do cliente. A satisfação do cliente deriva da proximidade entre as expectativas do comprador e o desempenho percebido do produto. Se o desempenho não alcançar totalmente as expectativas, o cliente fica desapontado; se alcançar as expectativas, ele fica satisfeito; e se exceder as expectativas, ele fica encantado. Esses sentimentos ajudam a definir se o cliente voltará a comprar o produto e se ele falará favorável ou desfavoravelmente sobre o mesmo para outras pessoas (KOTLER, 2000).

$\mathrm{Na}$ concepção de Engel, Blackwell e Miniard (2000), a pesquisa sobre descarte pode ser dividida em três categorias: descarte direto, reciclagem e remarketing.

- Descarte direto - nesse caso os autores comentam que é comum as pessoas formarem um tipo de ligação com algum produto, ou seja, formarem laços psicológicos, mas nada pode durar para sempre, gerando assim uma necessidade de descarte.

- Reciclagem - essa se tornou comum principalmente a partir do momento em que passou a se cobrar de forma obrigatória em algumas áreas. Nesses casos de obrigatoriedade, segundo os autores, a obediência varia de $25 \%$ a $90 \%$.

- Remarketing - essa categoria pode ser entendida com um exemplo típico do dia-a-dia, onde se percebe um aumento na venda de itens usados; até carros usados são vendidos em maior número nas revendedoras, se comparados aos carros novos.

Por meio da compreensão do processo decisório do consumidor, os profissionais podem descobrir porque as pessoas compram ou não produtos, e os motivos pelos quais escolhem seus fornecedores (STEFANO; FILHO, 2012). 


\section{PROCEDIMENTOS METOdOLÓGICOS}

Este estudo se classifica, quanto aos fins, como sendo exploratório e descritivo. Os meios que foram utilizados para o mesmo são: pesquisa bibliográfica, grupos de foco, entrevistas em profundidade e survey.

Para a pesquisa exploratória foram utilizados dados secundários por meio de materiais bibliográficos e também dados primários, através de uma abordagem qualitativa, utilizando-se do método direto de grupo de foco e de entrevistas em profundidade (MALHOTRA, 2001).

A pesquisa descritiva envolveu a realização de Survey, que se baseou em um questionário estruturado e aplicado a uma amostra com o objetivo de extrair informações específicas dos entrevistados. Este estudo, por sua vez, caracteriza-se em transversal único, onde foram extraídas amostras de entrevistados da população-alvo e as informações obtidas num único momento.

Para a coleta de dados bibliográficos foram realizadas pesquisas em livros e em estudos anteriores que focaram o tema, servindo de embasamento teórico através da visão de diversos autores, proporcionando conhecimentos mais aprofundados na área estudada. A pesquisa qualitativa aplicada através do modelo de grupo de foco contou com a participação de dez pessoas, que compraram um veículo usado no segundo semestre de 2011. Também foram realizadas duas entrevistas em profundidade com proprietários de lojas de veículos automotores. Em ambos os casos a amostra foi não-probabilística por julgamento (MALHOTRA, 2001).

No método de survey, pessoas de ambos os sexos que possuem veículos usados participaram da pesquisa. Aqui a amostragem não-probabilística por conveniência foi usada para buscar informações sobre um assunto de interesse (COOPER; SCHINDLER, 2003). Nessa etapa quantitativa da pesquisa foi elaborado um questionário com perguntas fechadas, o qual procurou abordar o comportamento dos consumidores no processo decisório de compra de veículos usados. Depois de elaborado o questionário, realizou-se um pré-teste com dez pessoas. Por meio disso, foi possível realizar alterações e ajustes necessários no questionário para que fossem coletadas informações mais precisas.

Foram entrevistadas 86 pessoas, com idade entre 18 e 55 anos. As atitudes foram mensuradas por meio de uma escala de Likert. Essa escala permitiu que os Revista Produção Online, Florianópolis, SC, v. 16, n. 2, p. 705-721, abr./jun. 2016. 
entrevistados demonstrassem seu grau de concordância às assertivas, variando de $1=$ Discordo Totalmente a $5=$ Concordo Totalmente.

Depois de realizadas as coletas de dados, os mesmos passaram por uma análise e interpretação, para que pudessem atender os objetivos do estudo. A pesquisa bibliográfica foi utilizada para embasar as interpretações de dados obtidas a partir da pesquisa qualitativa e da pesquisa quantitativa. As informações levantadas nos métodos de grupo de foco e entrevista em profundidade auxiliaram na interpretação dos dados obtidos por meio do survey.

$\mathrm{Na}$ fase descritiva, os dados coletados foram tabulados e analisados com ajuda de um software estatístico, onde foram usadas algumas ferramentas, tais como: distribuição de frequência, média aritmética simples, média ponderada e o Teste T. Para o Teste T foram analisadas as afirmativas que apresentaram uma diferença entre as médias com significância de $p<0,05$.

\section{APRESENTAÇÃO E ANÁLISE DOS RESULTADOS}

\subsection{Análise Descritiva do Processo Decisório de Compra}

A seguir serão apresentadas as análises feitas com base nos resultados obtidos pelas pesquisas quantitativas, as quais tratam do comportamento dos entrevistados no decorrer do processo decisório de compra de veículos usados. Buscando facilitar o entendimento dos dados coletados, agrupou-se o nível de concordância em três categorias, onde temos: Discordo (D), Nem Discordo e Nem Concordo (NN) e Concordo (C); ou seja, os resultados da discordância foram somados, assim como os da concordância, mantendo-se ainda as respostas dos que nem concordam e nem discordam. Para a elaboração dessas 50 assertivas foram consideradas as sete etapas citadas por Engel, Blackwell e Miniard (2000).

\subsubsection{Reconhecimento da Necessidade}

$\mathrm{Na}$ Tabela 1, que apresenta os resultados encontrados na primeira fase do processo decisório de compra, é possível destacar inicialmente as afirmativas em que os respondentes mostram maior grau de concordância nas afirmações: "Preciso de um veículo", com 77,9\%, e "compro um veículo apenas por necessidade, não por Revista Produção Online, Florianópolis, SC, v. 16, n. 2, p. 705-721, abr./jun. 2016. 
impulso", com 59,3\% das afirmações. Os resultados dessas assertivas mostram que a maior parte das pessoas necessita atualmente de um veículo, pois ele traz a todos o benefício de locomoção, mas, também, essa compra não é realizada por impulso, devido pelo fato da maioria dos respondentes já serem casados. Com isso, existem outras necessidades que vêm em primeiro lugar na vida dessas pessoas.

Nas afirmativas que apresentam maior grau de discordância entre os respondentes destaca-se com maior percentual a seguinte afirmação: "Tenho vontade de comprar ou trocar de carro quando meus amigos compram", com $80,3 \%$, seguida de: "Compro um carro para me sentir de acordo com meu grupo social", tendo $77,9 \%$ das respostas.

Tabela 1 - Reconhecimento da Necessidade

\begin{tabular}{|c|c|c|c|c|}
\hline RE CONHE CIMENTO DA NE CESSIDADE & D \% & $\begin{array}{l}\text { NN } \\
\%\end{array}$ & $\mathrm{C} \%$ & $\%$ con \\
\hline 1- Preciso de um veiculo. & 11,6 & 10,5 & 77,9 & 75,9 \\
\hline $\begin{array}{l}\text { 2- Compro um veiculo somente quando o meu está velho ou com } \\
\text { defeitos. }\end{array}$ & 44,2 & 34,9 & 21 & 43,6 \\
\hline $\begin{array}{l}\text { 3- Procuro melhorar o ano do meu veiculo e troco a cada dois ou três } \\
\text { anos. }\end{array}$ & 26,7 & 26,7 & 46,5 & 57,6 \\
\hline 4- Minha atividade profissional exige um veiculo semi-novo. & 60,4 & 16,3 & 23,3 & 35,5 \\
\hline $\begin{array}{l}\text { 5- Busco trocar de carro motivado por mudanças na familia } \\
\text { (nascimento de um filho, quando os filhos começam a crescer, etc.). }\end{array}$ & $\mathbf{5 5 , 8}$ & 24,4 & 19,8 & 35,2 \\
\hline 6-Compro um carro para me sentir de acordo com meu grupo social. & 77,9 & 11,6 & 10,5 & 23,8 \\
\hline $\begin{array}{l}\text { 7- Tenho vontade de comprar um carro quando meus amigos } \\
\text { compram. }\end{array}$ & 80,3 & 11,6 & 8,2 & 20,3 \\
\hline 8- Necessitamos de mais um veículo na familia. & $\mathbf{5 4 , 2}$ & 14 & 31,4 & 40,1 \\
\hline 9- Compro um veiculo apenas por necessidade, não por impulso. & 16,3 & 24,4 & 59,3 & 63,1 \\
\hline $\begin{array}{l}\text { 10- Troco de carro quando sei que o modelo do meu carro atual saiu } \\
\text { ou irá sair de linha de fabricação. }\end{array}$ & 64 & 22,1 & 14 & 32,2 \\
\hline $\begin{array}{l}\text { 11- Compro por impulsividade, se gostar do veiculo faço a compra, } \\
\text { m esmo que tenha que financiar a longo prazo. }\end{array}$ & 73,3 & 12,8 & 13,9 & 25 \\
\hline
\end{tabular}

(D) Discordo, (NN) Nem concordo - Nem discordo, (C) Concordo.

Fonte: Elaborado pelos autores

\subsubsection{Busca de Informações}

Nesta segunda fase do processo decisório de compra, as quatro afirmativas que mais obtiveram respondentes concordando foram, conforme Tabela 2: "Para comprar ou trocar meu veículo busco opinião e conselho de amigos", com $74,4 \%$; "Pesquiso em jornais/classificados, anúncios ou internet", tendo 79\%. Quando as pessoas buscam a opinião dos amigos, elas desejam ter uma maior segurança para decidir qual é o melhor veículo a ser comprado. Podem ainda fazer o uso da internet, jornais/classificados, acompanhadas dessas pessoas a quem eles buscam a Revista Produção Online, Florianópolis, SC, v. 16, n. 2, p. 705-721, abr.jjun. 2016. 
opinião, com a intenção de mostrar as suas alternativas e ouvir o conselho delas. Em terceiro há a afirmativa: "Visito diversas lojas em busca de informações sobre preço e qualidade", com $70,9 \%$ de escore.

Tabela 2 - Busca de Informações

\begin{tabular}{l|c|c|c|c}
\hline \multicolumn{1}{c|}{ BU SCA DE INFORMAĈ̣̃ S } & D \% & NN\% & C \% & $\%$ con \\
\hline 12-Para comprar meu veiculo busco opinião e conselho com amigos. & 12,8 & 12,8 & $\mathbf{7 4 , 4}$ & 70,6 \\
\hline 13-Pesqui so em jornais/dassificados, anúncios ou internet. & 11,6 & 9,3 & $\mathbf{7 9}$ & 73 \\
\hline $\begin{array}{l}\text { 14- Visito diversas 1ojas em busca de inform ações sobre o preço e } \\
\text { qualidade. }\end{array}$ & 14 & 15,1 & $\mathbf{7 0 , 9}$ & 68,6 \\
\hline $\begin{array}{l}\text { 15- Não busco inf., pois tenho uma marca pref. e só compro dessa } \\
\text { marca. }\end{array}$ & 77,9 & 11,6 & 10,5 & 24,1 \\
\hline $\begin{array}{l}\text { 16- Levo em consideração a opinião de membros da fam ilia para a } \\
\text { escolha do veiculo que pretendo comprar. }\end{array}$ & 12,8 & 23,3 & $\mathbf{6 3 , 9}$ & 67,2 \\
\hline $\begin{array}{l}\text { 17- Busco verificar o que as pessoas do meu nivel social ou minha } \\
\text { faix a etária costumam adquirir. }\end{array}$ & $\mathbf{6 9 , 8}$ & 19,8 & 10,5 & 29,1 \\
\hline $\begin{array}{l}\text { 18- Não pesquiso, vou direto à concessionária/oja que sempre } \\
\text { costum o ir para trocar de veiculo. }\end{array}$ & $\mathbf{8 2 , 5}$ & 10,5 & 7 & 22,4 \\
\hline \begin{tabular}{l} 
19-Busco inf. com mecânicos e chapeadores que conhecem veiculos \\
\hline
\end{tabular} & 19,7 & 31,4 & 48,9 & 60,2 \\
\hline
\end{tabular}

(D) Discordo, (NN) Nem concordo - Nem discordo, (C) Concordo.

Fonte: Elaborado pelos autores

\subsubsection{Avaliação das Alternativas}

Depois de detectada a necessidade de aquisição e também já realizada a busca de informações; é preciso decidir, dentre algumas alternativas, qual será comprada. Essa decisão requer bastante esforço dos consumidores, que por sua vez devem decidir a compra dentre as alternativas disponíveis (SOLOMON, 2002). $\mathrm{Na}$ Tabela 3 pode-se observar que os índices de concordância foram, na maioria das vezes, mais altos que os de discordância; assim, a afirmativa que possui maior nível de concordância, com 95,3\% das respostas, é: "Avalio a procedência e o estado de conservação do veículo". A seguinte afirmativa: "Levo em conta as características do veículo (marca, modelo, cor, potência, autonomia) não importando a loja" soma um total de $73,3 \%$ dos respondentes que concordam com isso.

Outra afirmação a se destacar, é: "Procuro por concessionária/loja que tenha uma grande variedade de marcas e modelos", apontando 60,5\% das intenções. Isso mostra que os compradores vão em busca de uma vasta quantidade de opções de veículos onde, muitas vezes, selecionam alguns para realizar uma avaliação mais detalhada. "Prefiro ir à loja em que já comprei um veículo, principalmente pela 
confiança que tenho e pela garantia oferecida", é outra assertiva em que houve uma concordância de $66,3 \%$.

Tabela 3 - Avaliação das Alternativas

\begin{tabular}{|c|c|c|c|c|}
\hline AVALIAC̣ÃO DAS ALTE RNATIVAS & D \% & NN $\%$ & C $\%$ & $\%$ con \\
\hline $\begin{array}{l}\text { 20- Procuro por revenda que tenha um a grande varied. de marcas e } \\
\text { modelos. }\end{array}$ & 16,3 & 23,3 & 60,5 & 63,4 \\
\hline 21- V ou a loja onde o preço é atraente (menor preço). & 24,4 & 25,6 & 50 & 58,1 \\
\hline 22 - Avalio a procedência e o estado de conservação do veiculo. & 3,5 & 1,2 & 95,3 & 83,1 \\
\hline $\begin{array}{l}\text { 23- Considero a opinião de amigos e costumo comprar o que eles } \\
\text { indicam. }\end{array}$ & 39,5 & 39,5 & 21 & 43,3 \\
\hline $\begin{array}{l}\text { 24- Prefiro ir à loja que já comprei um veiculo, principalm ente pela } \\
\text { confiança que tenho pela garantia oferecida. }\end{array}$ & 3,5 & 30,2 & 66,3 & 70,1 \\
\hline $\begin{array}{l}\text { 25- Levo em conta as caracteristicas do veiculo (marca, modelo, cor, } \\
\text { potência, autonom ia), não importando a loja. }\end{array}$ & 10,5 & 16,3 & 73,3 & 70,9 \\
\hline $\begin{array}{l}\text { 26- Sou capaz de pagar um pouco mais pelo veiculo, desde que as } \\
\text { opções de pagamento sejam mais atraentes. }\end{array}$ & 30,2 & 25,6 & 44,2 & 53,2 \\
\hline
\end{tabular}

(D) Discordo, (NN) Nem concordo - Nem discordo, (C) Concordo.

Fonte: Elaborado pelos autores

\subsubsection{Compra}

Engel, Blackwell e Miniard (2000) entendem que, para o vendedor ganhar a confiança do comprador e obter sucesso nas vendas, ele necessita de quatro variáveis: conhecimento e especialidade percebidos; honestidade percebida; conhecimento do cliente; e adaptabilidade. Diante da perspectiva destes autores, nota-se na Tabela 4 um grau de concordância de $81,4 \%$ dos respondentes, quando dizem realizar a compra ao serem bem atendidos e perceberem a sinceridade do vendedor.

Os participantes da pesquisa concordam (75,5\%) também que realizam a compra quando o carro que já possuem é aceito na negociação, como entrada de pagamento. Esse índice demonstra que, para os consumidores realizarem a troca do veículo atual, é necessário fazerem o uso desse veículo como entrada no pagamento; caso a loja/concessionária não aceite o mesmo, esse cliente estará propenso a procurar outra loja, logo, um concorrente. Quanto à opinião do cônjuge, $56,9 \%$ dos respondentes dizem que realizam a compra após ouvi-lo. 
Tabela 4 - Compra

\begin{tabular}{|c|c|c|c|c|}
\hline COMPRA & D $\%$ & NN\% & $\mathrm{C} \%$ & $\%$ con \\
\hline $\begin{array}{l}\text { 27- Compro quando sou bem atendido e percebo sinceridade do } \\
\text { vendedor. }\end{array}$ & 4,7 & 14 & 81,4 & 75,3 \\
\hline $\begin{array}{l}\text { 28- Compro quando aceita meu veiculo atual como entrada no } \\
\text { pagamento. }\end{array}$ & 5,8 & 18,6 & 75,5 & 71,8 \\
\hline 29-Compro quando consigo financiar a uma tax a de juro atraente. & 15,2 & 24,4 & 60,4 & 63,1 \\
\hline 30-Realizo a compra quando o vendedor oferece garantia & 8,2 & 18,6 & 73,3 & 70,9 \\
\hline $\begin{array}{l}\text { 31-Ef etuo a compra quando o veiculo atende às m inhas necessidades, } \\
\text { independente do preço cobrado. }\end{array}$ & 29,1 & 43 & 28 & 49,7 \\
\hline $\begin{array}{l}\text { 32- Compro somente quando preço e as condições de pagto. forem } \\
\text { atraentes. }\end{array}$ & 18,6 & 19,8 & 61,6 & 64,2 \\
\hline 33-Compro de acordo com as caracteristicas e beneficios do veiculo. & 2,3 & 15,1 & 82,6 & 73 \\
\hline 34- Realizo a compra depois de ouvir o cônjuge. & 19,8 & 23,3 & 56,9 & 61 \\
\hline
\end{tabular}

(D) Discordo, (NN) Nem concordo - Nem discordo, (C) Concordo.

Fonte: Elaborado pelos autores

\subsubsection{Consumo}

Percebe-se, de acordo com a Tabela 5, que nessa fase do processo decisório de compra, quando questionados sobre o uso do veículo após a compra, 94,2\% afirmam que fazem seu uso imediatamente após tomarem posse do mesmo. Do mesmo modo, a afirmação: "Procuro seguir as instruções que o vendedor me passa sobre o uso correto do veículo", apresenta uma concordância de 81,4\%.

No entendimento de Engel, Blackwell, Miniard (2000), no estágio pós-compra os consumidores empregam um grau de análise sobre os produtos, dependendo muito da importância de decisão na hora da compra e também pela experiência com a utilização do produto.

Tabela 5 - Consumo

\begin{tabular}{l|c|c|c|c}
\hline \multicolumn{1}{c|}{ CONSU MO } & D \% & NN\% & C \% & $\%$ con \\
\hline 35-Assim que faço a compra, uso imediatamente o veiculo. & 1,2 & 4,7 & $\mathbf{9 4 , 2}$ & 81,4 \\
\hline $\begin{array}{l}\text { 36- Procuro seguir as instruções que o vendedor me passa sobre o uso } \\
\text { correto do veiculo. }\end{array}$ & 4,7 & 14 & $\mathbf{8 1 , 4}$ & 74,4 \\
\hline 37-Uso o veiculo exclusivamente para o trabalho. & $\mathbf{6 2 , 8}$ & 29,1 & 8,2 & 31,4 \\
\hline 38-Uso o veiculo de maneira geral (trabalho e passeio). & 7 & 5,8 & $\mathbf{8 7 , 2}$ & 78,2 \\
\hline $\begin{array}{l}\text { 39- Se o veiculo não atender às minhas expec., procuro trocá-1o } \\
\text { imediat. }\end{array}$ & 19,8 & 33,7 & 46,5 & 57,3 \\
\hline
\end{tabular}

(D) Discordo, (NN) Nem concordo - Nem discordo, (C) Concordo.

Fonte: Elaborado pelos autores 


\subsubsection{Avaliação Pós-Consumo}

Na Tabela 6, a afirmativa: "Se fui bem atendido e realizei uma boa compra, volto a comprar na mesma loja", teve uma concordância de $87,2 \%$ dentre os respondentes. Neste sentido, Kotler e Armstrong (1998) dizem que é importante satisfazer um cliente devido ao fato de as vendas originarem-se de dois grupos básicos: novos clientes e clientes mantidos. Os autores explicam, ainda, que conquistar novos clientes custa mais caro do que mantê-los; assim, faz-se necessário satisfazê-los, pois estes vão voltar a comprar e, ainda, elogiar para outros.

Quando perguntados se já recomendaram a concessionária/loja para outras pessoas, $80,2 \%$ concordam. O boca a boca positivo pode ser um dos maiores ativos do profissional de marketing, enquanto o oposto pode ser verdadeiro, quando o conteúdo é negativo.

Tabela 6 - Avaliação Pós-Consumo

\begin{tabular}{|c|c|c|c|c|}
\hline AVALIAC̣AOO PÓS-COMPRA & D $\%$ & NN $\%$ & C $\%$ & $\% \operatorname{con}$ \\
\hline $\begin{array}{l}\text { 40- Após a compra, surgindo algum problema com o veiculo, a loja } \\
\text { em que comprei imediatamente resolve. }\end{array}$ & 15,1 & 45,3 & 39,5 & 57,8 \\
\hline $\begin{array}{l}\text { 41- Se fui bem atendido e fiz boa compra, volto a comprar na mesma } \\
\text { loja. }\end{array}$ & 1,2 & 11,6 & 87,2 & 72,6 \\
\hline 42 -Não volto mais à loja que me negou garantia do veiculo. & 15,1 & 15,1 & 69,8 & 69,8 \\
\hline $\begin{array}{l}\text { 43- Se ficar satisfeito ou insatisfeito com a compra, compartilho essa } \\
\text { experiência com amigos e conhecidos. }\end{array}$ & 7 & 9,3 & 83,7 & 75,3 \\
\hline 44-Eu já recomendei a concessionária/ loja para outras pessoas. & 2,3 & 17,4 & 80,2 & 76,2 \\
\hline $\begin{array}{l}\text { 45- Me frustrei após a com pra, pois certas coisas não ocorreram } \\
\text { conforme o que foi combinado no momento da aquisição do veiculo }\end{array}$ & 38,4 & 29,1 & 32,5 & 47,4 \\
\hline $\begin{array}{l}\text { 46-Costumo voltar a loja para obter mais inf. sobre o veiculo que } \\
\text { comprei. }\end{array}$ & 25,6 & 34,9 & 39,5 & 52 \\
\hline
\end{tabular}

(D) Discordo, (NN) Nem concordo - Nem discordo, (C) Concordo.

Fonte: Elaborado pelos autores

\subsubsection{Descarte}

$\mathrm{Na}$ Tabela 7 pode ser observado que os respondentes não procuram ficar com seus veículos por um longo período de tempo; $77,9 \%$ deles discordam da afirmativa: "Troco de veículo somente quando ele sai de linha". Outra afirmativa em que houve discordância entre a maioria dos respondentes, foi: "Quando meu veículo está velho ou com defeitos, procuro reformar e ficar por mais algum tempo", com 
45,4\%; e com maior nível de discordância, está a afirmação: "Uso o veículo até o limite e depois vendo como sucata", representando $90,7 \%$ das opiniões.

As três assertivas anteriores destacam que os consumidores buscam por uma troca periódica dos seus veículos, evitando certas perdas devido à depredação pelo uso. De acordo com a única afirmação em que houve concordância, 61,6\% dizem que usam o veículo até determinado tempo e depois vendem.

Tabela 7 - Avaliação Pós-Consumo

\begin{tabular}{|c|c|c|c|c|}
\hline DE SCARTE & D $\%$ & NN\% & C $\%$ & $\% \operatorname{con}$ \\
\hline 47- Uso o veiculo até determinado momento e depois vendo. & 19,8 & 18,6 & 61,6 & 61,6 \\
\hline 48-Troco de veiculo somente quando ele sai de linha & 77,9 & 20,9 & 1,2 & 25,3 \\
\hline $\begin{array}{l}\text { 49- Quando meu veiculo está velho e com defeito, procuro reformar e } \\
\text { ficar por mais algum tempo. }\end{array}$ & 45,4 & 39,5 & 15,1 & 39,5 \\
\hline 50- Uso o veiculo até o limite e depois vendo como sucata. & 90,7 & 8,1 & 1,2 & 14,5 \\
\hline
\end{tabular}

(D) Discordo, (NN) Nem concordo - Nem discordo, (C) Concordo.

Fonte: Elaborado pelos autores

\subsection{Processo Decisório de Compra de acordo com Sexo e Estado Civil}

A fim de obter informações mais aprofundadas neste estudo, optou-se por analisar outras variáveis, com a ajuda do "teste T", o qual mede o nível de significância entre dois grupos; assim, foi possível analisar as diferenças entre sexo (masculino e feminino) e ainda o estado civil (solteiro e casado), nas etapas do processo decisório de compra. Dessa forma, na sequência do estudo estão expressas as afirmativas que apresentaram diferenças entre as médias em uma significância menor de 0,05.

A Tabela 8 apresenta as afirmativas das três etapas do processo decisório de compra em que houve a diferença estimada quanto ao sexo dos participantes da pesquisa, sendo as etapas: Busca de Informação; Consumo; Avaliação PósCompra. 
Tabela 8 - Etapas do Processo Decisório de Compra X Sexo

\begin{tabular}{|c|c|c|c|}
\hline BUSCA DE INFORMAC̣ÃO & M & $\mathbf{F}$ & $\mathbf{P}$ \\
\hline $\begin{array}{l}\text { 16- L evo em consideração a opinião dos membros da familia para a escolha do } \\
\text { veiculo que pretendo comprar. }\end{array}$ & 3,55 & 4,00 & 0,042 \\
\hline CONSUMO & M & $\mathrm{F}$ & $P$ \\
\hline $\begin{array}{l}\text { 36- Procuro seguir as instr. que o vendedor me passa sobre o uso correto do } \\
\text { veiculo. }\end{array}$ & 3,85 & 4,27 & 0,021 \\
\hline AVALIACÃO PÓS-CONSUMO & M & $\mathbf{F}$ & $\mathbf{P}$ \\
\hline $\begin{array}{l}\text { 43- Se ficar satisfeito ou insatifeito com a compra compartitho essa } \\
\text { experiência com amigos e conhecidos. }\end{array}$ & 3,87 & 4,35 & 0,018 \\
\hline
\end{tabular}

(M) Masculino, (F) Feminino, (P) Significância

Fonte: Elaborado pelos autores

A partir da Tabela 8, percebe-se que as mulheres consideram mais a opinião dos familiares na hora de comprar um veículo. Na afirmativa: "Procuro seguir as instruções que o vendedor me passa sobre o uso correto do veículo", também tem como concordância a maioria das mulheres, do mesmo modo que são elas as maiores responsáveis por compartilhar com amigos e conhecidos suas experiências de compra.

$\mathrm{Na}$ Tabela 9 também foram agrupadas as afirmativas que apresentaram diferença significativa entre casados e solteiros. Na afirmativa "tenho vontade de comprar ou trocar de carro quando meus amigos compram", percebe-se que são os solteiros que mais se preocupam com isso. Nas outras duas afirmações: "Visito diversas lojas em busca de informação sobre preço e qualidade", e "Sou capaz de pagar um pouco mais pelo veículo, desde que as opções de pagamento sejam mais atraentes", também tem os solteiros como os maiores representantes.

Tabela 9 - Etapas do Processo Decisório de Compra X Estado Civil

\begin{tabular}{|c|c|c|c|}
\hline RE CONHE CIMENTO DA NECE SSIDADE & $\mathrm{S}$ & $\mathrm{C}$ & $\mathbf{P}$ \\
\hline 07-T enho vontade de comprar ou trocar de carro quando meus amigos compram. & 2,11 & 1,59 & 0,016 \\
\hline BUSCA DE INFORMAC̣ÃO & $\mathbf{S}$ & $\mathrm{C}$ & $P$ \\
\hline 14-Visito diversas lojas de veiculos em busca de inf. sobre preço e qualidade. & 4,05 & 3,52 & 0,020 \\
\hline AVALIAC̣ÃO DAS ALTE RNATIVAS & $\mathbf{S}$ & $\mathrm{C}$ & $\mathbf{P}$ \\
\hline $\begin{array}{l}\text { 26- Sou capaz de pagar um pouco mais pelo veiculo, desde que as opções de } \\
\text { pagamento sejam mais atraentes. }\end{array}$ & 3,40 & 2,91 & 0,036 \\
\hline
\end{tabular}

(S) Solteiro, (C) Casado, (P) Significância

Fonte: Elaborado pelos autores 


\section{CONCLUSÃO}

O setor de veículos usados está em um momento de grande crescimento, onde a cada dia mais consumidores potenciais se tornam novos clientes em alguma empresa ofertante desse segmento. Esses clientes, na busca pelo veículo que mais Ihes interessa, passam pelas fases do processo decisório de compra, onde levam em conta muitas variáveis até chegar o momento da decisão de compra. Esse processo de compra deve ser visto pelas empresas como sendo o caminho na busca pelo cliente potencial, ou na própria retenção dos que já possui.

$\mathrm{Na}$ fase de reconhecimento da necessidade percebeu-se que a maioria dos respondentes afirmou que necessita de um veículo, mas não se sente estimulado a comprar quando os amigos o estão fazendo, nem mesmo para se sentir de acordo com seu grupo social.

Quando busca informações, a opinião da família e dos amigos é levada muito em conta, bem como pesquisas em jornais/classificados, internet e visitas a diversas lojas de veículos. A maior parte dos entrevistados não busca verificar o que as pessoas do mesmo nível social e na mesma faixa etária costumam comprar.

$\mathrm{Na}$ avaliação das alternativas de compra, os consumidores procuram por lojas onde já tenham comprado um veículo antes, isso pela confiança que possuem. Também procuram por lojas que tenham uma grande variedade de marcas e modelos, e avaliam principalmente a procedência e o estado de conservação dos veículos, considerando ainda as características dos mesmos quanto à cor, potência e autonomia.

Os respondentes consideram que para realizar a compra é necessário serem bem atendidos e perceberem a sinceridade do vendedor, com $81,4 \%$ das respostas, caso contrário pode haver a desistência de comprar. A compra é feita quando o carro em posse dos clientes é aceito como entrada no pagamento e, ainda, quando Ihes é oferecido garantia do veículo.

Outra característica a se destacar é que os consumidores, após fazerem a compra, usam os veículos imediatamente e buscam seguir as instruções de uso correto passadas pelos vendedores. Nota-se ainda que a maioria usa seu veículo para ambas as atividades, trabalho e lazer.

$\mathrm{Na}$ avaliação dos resultados após o consumo, a maioria dos respondentes afirma que, ao fazer uma boa compra, volta a comprar nessa mesma loja e também

Revista Produção Online, Florianópolis, SC, v. 16, n. 2, p. 705-721, abr.jun. 2016. 
a recomenda para os outros. E ainda afirma que não volta a comprar em lojas que negaram a garantia do veículo comprado.

Quanto ao descarte, não é de característica dos participantes ficarem com o veículo por um longo período de tempo; diante disso, eles asseguram que usam seus carros de dois a três anos e depois vendem ou trocam por outro.

Outras ilações foram obtidas mediante a comparação entre sexo (masculino e feminino) e estado civil (solteiro e casado) nas etapas do processo decisório de compra. Foi possível concluir que as mulheres levam mais em conta as opiniões da família para comprar um veículo, como também procuram seguir as instruções passadas pelos vendedores para o uso correto do mesmo. Na comparação entre os sexos, identificou-se também que as mulheres compartilham mais suas experiências de compra com amigos e conhecidos.

$\mathrm{Na}$ comparação entre solteiros e casados, a maioria das diferenças ficam por conta de uma concordância maior dos solteiros, onde os mesmos têm maior interesse em trocar de carro quando seus amigos compram, assim como são eles que mais visitam diversas lojas para buscarem informações sobre preço e qualidade, levando em conta ainda as opções de pagamento, nem que para isso paguem um pouco a mais pelo veículo.

Espera-se que o presente estudo tenha uma contribuição positiva para o setor de veículos usados, no sentido de orientar estratégias de marketing para qualificar o processo de comercialização das empresas que atuam nesse segmento. Outrossim, é possível conduzir ações no sentido de aperfeiçoar o relacionamento entre as empresas e seus clientes, bem como estimular as vendas e aumentar os lucros, fazendo que com isso o setor possa se desenvolver cada vez mais.

\section{REFERÊNCIAS}

BARROS, M.A. B.; LOPES, G. M. B.; WANDERLEY, M. B. Tipologia do Consumo de Frutas: Um Estudo Sobre o Comportamento do Consumidor de Banana. Revista Produção Online, Florianópolis, SC, Edição especial/dezembro de 2007. Artigo selecionado dos anais - XXVII Encontro Nacional de Engenharia de Produção, 2007.

CHEN, Y. Multiple criteria decision analysis: classification Problems and Solutions. 2006. $184 \mathrm{f}$. Thesis (Doctor of Philosophy) University of Waterloo, Waterloo,Ontario,Canada, 2006.

COOPER, D. R.; SCHINDLER, P. S. Métodos de pesquisa em administração. São Paulo: Bookmann, 2001. 
ENGEL, J. F; BLACKWELL, R.; D; MINIARD, P. W. Comportamento do consumidor. Rio de Janeiro: LTC 2000.

GIGLIO, E. Comportamento do consumidor e a gerência de marketing. São Paulo: Pioneira, 1996.

KOTLER, P. Administração de marketing. São Paulo: Prentice Hall, 2000.

KOTLER, P.; ARMSTRONG, G. Princípios de marketing. 7. ed. RJ: Prentice Hall, 1998.

LEMOS, R. F. Avaliação de atributos de compra no processo de aquisição de automóveis de alto valor. Porto Alegre-RS: PUCRS, 2007. Mestrado em Administração e Negócios.

MAGALHÃES, G. F. P. Teorias da demanda e do comportamento do consumidor. Viçosa: editora UFV, 2004.

MALHOTRA, N. K. Pesquisa de marketing: uma orientação aplicada. 3. ed. Porto Alegre, Bookman, 2001.

MATTAR, F. N. Pesquisa de marketing: metodologia, planejamento, execução, análise. 2. ed. São Paulo: Atlas, 1994.

MECCA, S. M.; COLAUTO, R. D.; BEUREN, I. M. Variáveis Determinantes da Precificação Baseada no Valor para o Consumidor em Instituições de Ensino Superior Privada. Revista Produção Online, Florianópolis, SC, v. 5, n. 2, Jun. 2005.

MINTZBERG, H.; RAISINGHANI, D.; THÉORÊT, A. The structure of "unstructured" decision processes. Administrative Science Quarterly, Ithaca, v. 21 n. 2, p. 246-275, 1976. http://dx.doi.org/10.2307/2392045

NUTT, P. C. The identification of solution ideas during organizational decision making.

Management Science, Linthicum, v.39, n.9, p.1071-1085, sep. 1993.

SAATY, T. L. Decision making with the analytic hierarchy process. International Journal of Services Sciences, v. 1, n. 1, 2008. http://dx.doi.org/10.1504/IJSSCI.2008.017590

SCHIFFMANN, L. G; KANUK, L. L. Comportamento do consumidor. Rio de Janeiro: LTC, 2000.

SHETH, J. N; MITTAL, B.; NEWMAN, B. I. Comportamento do cliente. São Paulo: Atlas, 2001.

SOLOMON, M. R. Comportamento do consumidor: comprando, possuindo e sendo. 5. ed. Porto Alegre: Bookman, 2002.

STEFANO, N. M.; FILHO, N. C. Percepção dos Consumidores: Atributos Considerados Importantes nas Embalagens. Revista Produção Online, Florianópolis, SC, v.12, n. 3, p. 657-681, jul./set. 2012. http://dx.doi.org/10.14488/1676-1901.v12i3.962

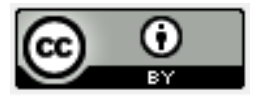

Artigo recebido em 30/07/2015 e aceito para publicação em 06/04/2016

DOI: $\underline{\text { http://dx.doi.org/ 10.14488/1676-1901.v16i2.2103 }}$

Revista Produção Online, Florianópolis, SC, v. 16, n. 2, p. 705-721, abr./jun. 2016. 